\title{
The Role of Live Visuals in Audience Understanding of Electronic Music Performances
}

\author{
Nuno N. Correia \\ Madeira-ITI, U. Madeira \\ Funchal, Portugal \\ nuno.correia@staff.uma.pt
}

\author{
Deborah Castro \\ Madeira-ITI, U. Madeira \\ Funchal, Portugal \\ deborah.castro@m-iti.org
}

\author{
Atau Tanaka \\ Goldsmiths, U. London \\ London, UK \\ a.tanaka@gold.ac.uk
}

\begin{abstract}
There is an identified lack of visual feedback in electronic music performances. Live visuals have been used to fill in this gap. However, there is a scarcity of studies that analyze the effectiveness of live visuals in conveying feedback. In this paper, we aim to study the contribution of live visuals to the understanding of electronic music performances, from the perspective of the audience. We present related work in the fields of audience studies in performing arts, electronic music and audiovisuals. For this purpose, we organized two live events, where 10 audiovisual performances took place. We used questionnaires to conduct an audience study in these events. Results point to a better audience understanding in two of the four design patterns we used as analytical framework. In our discussion, we suggest best practices for the design of audiovisual performance systems that can lead to improved audience understanding.
\end{abstract}

\section{CCS CONCEPTS}

- Human-centered computing $\rightarrow$ Graphical user interfaces; Information visualization; • Applied computing $\rightarrow$ Performing arts;

\section{KEYWORDS}

Audiovisuals, live visuals, music, performance, audience

\section{ACM Reference Format:}

Nuno N. Correia, Deborah Castro, and Atau Tanaka. 2017. The Role of Live Visuals in Audience Understanding of Electronic Music Performances. In Proceedings of AM '17, London, United Kingdom, August 23-26, 2017, 8 pages.

https://doi.org/10.1145/3123514.3123555

\footnotetext{
Permission to make digital or hard copies of all or part of this work for personal or classroom use is granted without fee provided that copies are not made or distributed for profit or commercial advantage and that copies bear this notice and the full citation on the first page. Copyrights for components of this work owned by others than the author(s) must be honored. Abstracting with credit is permitted. To copy otherwise, or republish, to post on servers or to redistribute to lists, requires prior specific permission and/or a fee. Request permissions from permissions@acm.org. AM '17, August 23-26, 2017, London, United Kingdom

(c) 2017 Copyright held by the owner/author(s). Publication rights licensed to Association for Computing Machinery.

ACM ISBN 978-1-4503-5373-1/17/08_..\$15.00

https://doi.org/10.1145/3123514.3123555
}

\section{INTRODUCTION}

Laptops have become a common tool in electronic music performances, with the appearance of powerful portable computers capable of real-time audio manipulation. However, the introduction of the laptop on the stage also brought with it an absence of visual feedback and gestural information regarding the performer's actions to the audience $[3,21]$. Amongst the approaches artists have taken is to use live visuals in electronic music performances to compensate for this absence [12].

We can find roots to today's approaches in live visuals in the experiments of the early-mid 20th century, with artists such as Oskar Fischinger combining elaborate film projection setups with music [25]. In turn, these influenced a generation of artists who would collaborate with live music artists in the 1960s and 1970s, with psychadelia-influenced approaches such as liquid projections [26]. The popularization of powerful personal computers with multimedia capabilities in the 1990s empowered a new generation of visual and audiovisual performers to generate and manipulate digital content in real time, live [33]. Audiovisual (AV) artists often create their own systems for performance, with a DIY approach, using software and programming environments such as Max/MSP, PureData, Processing and openFrameworks [11]. Salter describes that this practice adopted "a long litany of names such as audiovisual performance, real-time video, live cinema, performance cinema, and VJ culture" [33].

AV artists have aimed to combine sound and image for different reasons. One of these is to achieve a "total artwork" or "gesamtkunstwerk", using a "common urgence of every art towards the most direct appeal to a common public" [35], or in other words a "hypermediacy" [5]. Another approach has been to overcome the above-mentioned problem of lack of visual feedback in electronic music performances, by conveying visually to an audience, via video projection, all the "elements implied on the process of making their own music" [21], or in other words contributing to "immediacy" [5].

Practitioners have pursued two main paths to visualization: 1) using graphical correspondences more or less tightly mapped to sound and interaction parameters, defined as audiovisual performance, an "interconnection between sound and image, which sometimes becomes apparent and at other 
times remains intuitive" [6], and 2) projecting to the audience the code generated by music performers who use programming techniques to produce sound, a practice known as "live coding" [8]. In this paper, we will focus on the former. These experiences might carry risks of obscuring this understanding, not clarifying it: "visuals are an overpowering medium and can easily detract performance" [22]. Moreover, they created new issues regarding audience understanding of the processes and interaction behind the visuals.

Most studies that focus on the lack of visual feedback in laptop music and audiovisual performances (such as [21]) have approached this problem from the perspective of the performer. We propose to address this from the perspective of the audience, to answer the following research question: "What design approaches in laptop-based audiovisual performances can be more conducive to audience understanding of the performer's actions?" To answer it, we have developed a study involving the participatory design and development of a series of audiovisual projects, and their presentation in two public performance events, where audience studies were conducted.

\section{RELATED WORK}

\section{Audience Research}

The audience, one of the constituents of communication process, has been traditionally considered a passive or, even, an "invisible" and "mute" agent [36]. Semiotics and media studies started to explore a possibility of an active role. For example, interpretative media theory is based on the assumption that media texts are polysemic and open to individuals' interpretations [15]. Likewise, the concept of open text coined by Eco [14] refers to the multiple readings a single text may embrace beyond the one envisaged by the author. However, the asymmetry (or lack of correspondence) between the codes used by the reader and the author may lead to distorted communication [19].

Different methods have been used to understand spectators' responses to cultural objects (e.g. movies, novels, plays, songs). The nature of these objects affects the relationship between them and the audience. For instance, a reading audience usually engages with a stable text in privacy, while a theater audience not only interacts with a "transitional cultural object" but can also be part of a "collective effervescence" [17]. The nature of the cultural object will, therefore, determine the type of audience analysis carried out.

In the performing arts, different approaches to audience studies have been pursued. The research project "Watching Dance: Kinesthetic Empathy" [31] combined both qualitative audience methods and neurophysiological research to analyze how spectators respond to, and identify with, dance during and after the performance. Albert [1] analyzed how dancers and audience members react to choreographed and improvised movements in social dance by using conversation and video analysis. In their exploration of the tele-presence and performing arts convergence, Cesar et al. [7] used galvanic skin response sensors to analyze the engagement of theatre remote audiences, while Radbourne et al. [29] conducted focus groups to measure quality in theatrical works and live music concerts with an emphasis on potential reattendance.

In music, Jaimovich et al. [20] designed an installation to collect large samples of physiological and self-reported data using questionnaires to analyze people's emotional reaction to recorded music. In order to explore the response of young adults to a chamber music concert, Dearn and Pitts [13] relied on the combination of questionnaires, Write-Draw cards and focus groups. Lai and Bovermann [23] carried out semi-structured interviews with participants of a live aural performance with electronic instruments "to understand the communication flow and the engagement between performer and audience”. In this paper, we employed questionnaires to analyze the perceived correlation, from the audience's point of view, between the actions of the performer and visuals the perceived transparency of the performance.

Fels [16] defines transparency as "the psychophysiological distance, in the minds of the player and the audience, between the input and the output of a device mapping". On the basis that music is a multisensory phenomenon [34], visual kinematic information from an event (e.g. performer actions) has been documented to be a crucial factor in the communication of meaning [28] and in the emotional reactions evoked [34] within the audience. Nonetheless, electronic music performances are often sensor or laptop-based, which are not always visible to the public and whose usage does not require big gestures and actions from the performer. The configuration of electronic music performances transmits to the spectator little or, even, no-information about what is happening on the stage, unlike performances with acoustic instruments [3]. This may result in an unclear cognitive link between the sound and the performer's actions or, in the terminology of Fels et al. [16], in a lack of transparency.

In electronic musical instruments, the decoupling of control and sound makes transparent mapping a challenge [16]. Transparency can be explored from two different points of view: that of the player and that of the audience. On the one hand, "transparency of a mapping for the player depends both on cognitive understanding and on physical proficiency". On the other hand, the audience may need "to have an understanding of how the instrument works to appreciate the proficiency of the player" which may be affected by, for example, their own cultural knowledge [16]. Interest and enjoyment levels may be independent of the audience's 
technical knowledge. Indeed, Bin et al. [4] noted that having access to tutorials on digital musical instruments before the performance increased the audience's know-how on the topic but did not seem to have an impact on these quantities.

Gurevich and Fyans [18] pose the following questions regarding the spectator's experience: 1) Address: How does the spectator know that the performer is interacting with the system?, 2) Attention: How does the spectator know that the system is responding to the performer?, 3) Action: How does the spectator think the user controls the system?, 4) Alignment: How does the spectator know that the system is doing the right thing?, 5) Accident: How does the spectator know when the performer of the system has made a mistake? In particular, we focus our attention on "action" - called "mapping comprehension" by Barbosa et al. [2] - that digs into audience's understanding of how the mapping between input (cause) and output (effects) functions. In other words: "How clear is the relationship between the performer's actions and, in our particular case, the audiovisual result?".

\section{Taxonomy for Audiovisual Systems and AVUI}

There are a large variety of real-time audiovisual art approaches that have been used in electronic music performances. Ribas [32] has created a taxonomy that classifies these different systems, based on four categories:

(1) Audiovisual entities, assuming "distinct procedural behaviors and responses to interaction": pieces composed of distinct individual elements, "mostly graphic shapes or moving pixels", which have "associated sound excerpts or loops, either to graphic forms or to an overall visual configuration".

(2) Interactive sounding shapes, where specific audiovisual elements are not necessarily created through the user's interaction, "but rather chosen, selected, altered, added or activated - reconfigured within the possibilities given by an existing repertoire devised within the system".

(3) Sounding figurations, consisting of visual elements that can be drawn or created by "screen-based and mouseoperated systems" and "whose properties are mapped to the production of synthetic sounds". In this category, nothing happens without human interaction, since "it is exactly human expression that the system is devised to integrate and express as its subject matter", producing "consistent responses to user input". This relates to Levin's work and research on painterly interfaces for audiovisual performance [24].

(4) Audiovisual reactions to interactions, where "changes to the audiovisual surface are a response to the participants' combined actions", often gestural. Reactions to the behavior are indeterminable: "there can be no linear correspondence" between an interaction and an audiovisual reaction "due to the fluctuating nature of the input data".

Looking at Ribas's taxonomy [32] from the perspective of audience understanding, the categories of audiovisual entities and sounding figurations seem more conductive to audience understanding. The former, because discreet user interactions are mapped to each entity, allowing for a more analytical representation. The latter, because of its inherent tight and consistent mapping between drawing and audiovisual result. These two categories relate to our concept of Audiovisual User Interface (AVUI) [11], where "UI, audio and visualization are interconnected and integrated", leading to clear audiovisual responses to interaction.

Interactive sounding shapes and audiovisual reactions seem to be on the other side of the spectrum. The former, because they are not necessarily created through the performer's interaction. The latter, because of the absence of linear mapping between interaction and reaction. To validate and further develop the nascent AVUI concept, we conducted the hackathons as a way to get audience feedback on the prototypes made by our artists. This led to broader insights about the role of visuals in the audience understanding of electronic music performance, which we report here.

\section{METHODS}

\section{Preliminary Stage: Interviews}

In previous research, we adopted a participatory design approach for the development and study of software for AV performances. We conducted interviews with 12 audiovisual performers, and asked them about their practice, the creative tools they use, and also their needs and desires as performers. One of the key themes identified in the analysis of the interviews was related to the communication of the performance process to the audience, and audience understanding [9].

\section{Audiovisual Projects}

The topic of audience understanding, and other key themes detected, informed a sketching workshop, and two hackathons (Gen.AV 1 and 2), on the topic of creating new tools for performance with generative audiovisuals. Five projects were created in Gen.AV 1, and six in Gen.AV 2. In [11], we have reported on these hackathons, and subsequent evaluation of projects. This evaluation consisted of tests by other performers of the projects, over a period of around one week, followed by interviews to gather feedback. The procedures followed were:

- Hackathon $>$ Audience Study $>$ Peer Evaluation

These procedures were repeated twice, in succession (once for Gen.AV 1 and another for Gen.AV2). We will now present the relevant projects resulting from this process, where user 


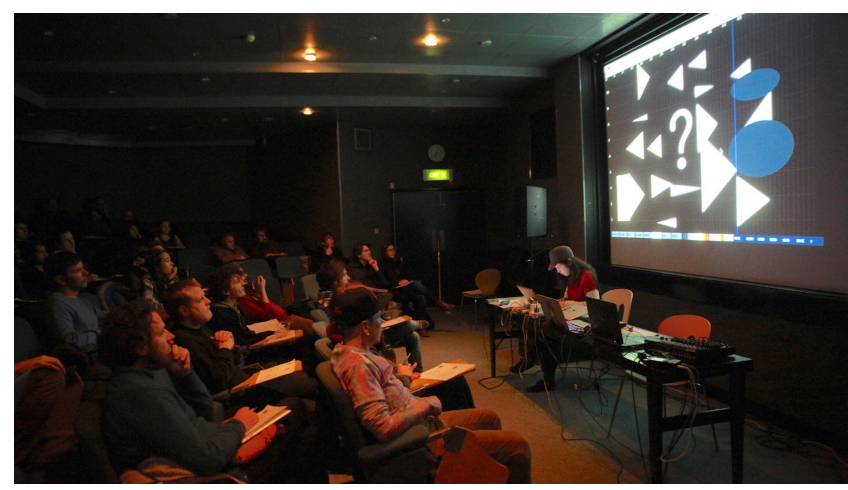

Figure 1: Image from first event, Modulant project.

interface elements were often integrated into sound visualizations, creating audiovisual entities, or AVUI.

Four projects were presented for audience evaluation at the Gen.AV 1 event. ABP is an animation engine and sound visualizer where the user can define visual parameters using an overall GUI (Graphical User Interface). Esoterion Universe starts with an empty $3 \mathrm{D}$ space that can be filled with planet-like audiovisual objects. GS.avi is an instrument that generates spatial visualizations and music from the gestures of a performer. Modulant allows for drawing images, which are then sonified. Six projects were presented at Gen.AV 2 event. Butterfly allows for the visualization and control of four audio synthesizers, by manipulating four icons in the screen. Cantor Dust generates, displays, and sonifies cantor set fractals. EUG (Esoterion Universe Gestenkrach) further develops Esoterion Universe from Gen.AV 1, adding $3 \mathrm{D}$ gestural control. OnTheTap plays with the tactile, analog feel of tapping surfaces as interaction input, combined with a GUI. residUUm allows for the creation of audiovisual particles with a specific lifespan, volume and panning [27]. Wat creates a chaotic audiovisual texture based on cellular automata, distributed in a rectangular 3D space. More information about all Gen.AV projects: (http://www.gen-av.org) and $[10,11]$.

These 10 projects can be mapped to Ribas's taxonomy for audiovisual pieces [32]:

(1) Butterfly, Esoterion University, EUG and residUUm can be considered audiovisual entities, as they are composed of individual elements, with distinctive graphic shapes and associated sounds, and also a related userinterface.

(2) ABP, Cantor Dust and OnTheTap can be classified as interactive sounding shapes, as they do not intended to represent specific sounds, but consist of generic graphics reacting to the overall sonic landscape, with the possibility of reconfiguring both audio and visuals

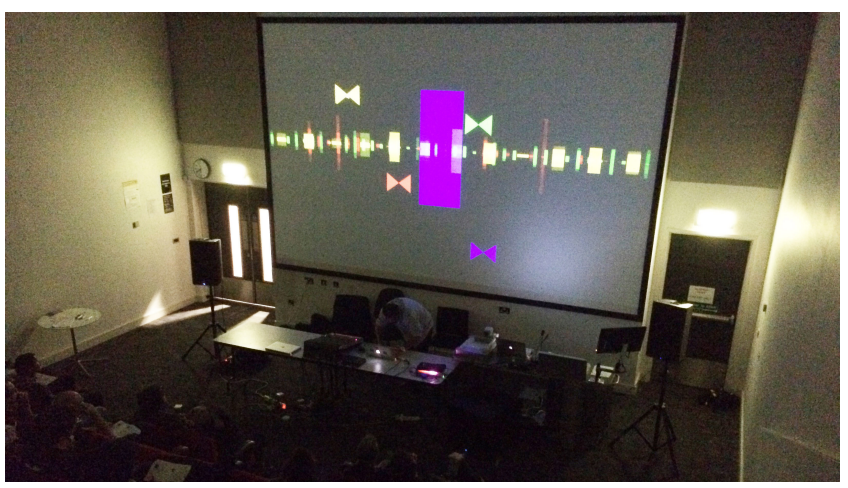

Figure 2: Image from second event, Butterfly project.

by means of an interface independent from the visual output.

(3) Modulant belongs to the sounding figurations category, as it consists of graphical elements that are drawn and mapped to the production of synthetic sound.

(4) GS.avi and Wat can be considered as part of the audiovisual reactions to interactions category, as changes to the audiovisual surface are a response to the performer's gestural actions, in a non-linear correspondence.

\section{Audience Studies}

In order to study audience experience in audiovisual performances, we organized two public events, one per hackathon, at Goldsmiths, University of London, in February (Figure 1) and July 2015 (Figure 2). Each project was presented in a tenminute performance, followed by a short discussion by the authors (around five minutes). In these events, we distributed questionnaires to the audience, with questions targeting each of the projects, four for Gen.AV 1 and six for Gen.AV 2 (one of the five Gen.AV 1 projects was left out of questionnaires due to late completion and last minute addition to event). In Gen.AV 1, 45 respondents answered the questionnaire, and 34 respondents in Gen.AV 2. The audience filled in the questionnaires in the short intervals between project performances.

The questionnaires consisted of three pairs of questions, repeated according to the number of projects (four for Gen.AV 1 and six for Gen.AV 2). Each pair consisted of a 5-point likert scale, and an open-ended question. Two of the pairs asked concern variety/diversity of audio and visual content, and relatedness between both modalities:

1) Did you find that the audiovisuals were varied and diverse? Rate: (1-5)

Complete the sentence: The audio and visuals were...

2) Did you find that sounds and visuals were 
The Role of Live Visuals in Audience Underst. of Elect. Music Perf. AM '17, August 23-26, 2017, London, United Kingdom

well related? Rate: (1-5)

Complete the sentence: The relationship between

sounds and visuals was...

These two pairs of questions are outside the scope of this paper. A third pair of our questions related to audience understanding of the performer's actions:

3) Did you find the connection between the per-

former's actions and the audiovisual result un-

derstandable? Rate: (1-5)

Complete the sentence: The performance was...

This was informed by Gurevich and Fyans's “audience questions" presented above, namely the "action" one [18]: "How does the spectator think the user controls the system?". In our formulation, members were asked to rate 1-5, from 1"not understandable at all", to 5-"very understandable". They were also asked to provide further insight on the topic in an open-ended question, by requesting them to complete the sentence "The performance was...".

\section{RESULTS}

45 audience members that answered the questionnaire in the Gen.AV 1 event, with an average age of 29. In terms of gender, 27 identified themselves as male, 12 as female, and 6 did not indicate gender. From the Gen.AV 1 audience members, 69\% had experience as practitioner in audio and/or visuals: $27 \%$ had experience as visual artist, visual designer or VJ, $18 \%$ as musician or DJ, and $24 \%$ in both. Age average of the 34 respondents to the Gen.AV 2 questionnaire was 33. In this case, 19 were male, 14 female, and 1 did not fill in this section. From the Gen.AV 2 audience members, 79\% had experience as practitioners: $26 \%$ as visual artist, visual designer or $\mathrm{VJ}$, $38 \%$ as musician or DJ, and $15 \%$ in both. The event was promoted at the location of the event, Goldsmiths, University of London, a university with a strong arts and music tradition, and at the London Music and Video Hackspace communities. Therefore the profile of the audience fits with our expectations - an audience composed of members familiar with diverse music and audiovisual performance practices.

Figure 3 presents the summary of the results obtained from the question on audience understanding of performers actions (Likert scale) as a boxplot. Projects Esoterion Universe and Modulant from Gen.AV 1, and Butterfly, EUG and residUUm from Gen.AV 2 obtained the highest results (Modulant with a median of 5 , the others with a median of 4). As we presented in the Methods section, these are the projects corresponding to the audiovisual entities and sounding figurations categories. This confirms our hypothesis that projects in these categories have higher potential for audience understanding.

The sounding figurations approach of Modulant was particularly successful: "Interesting and clear, it was quite easy

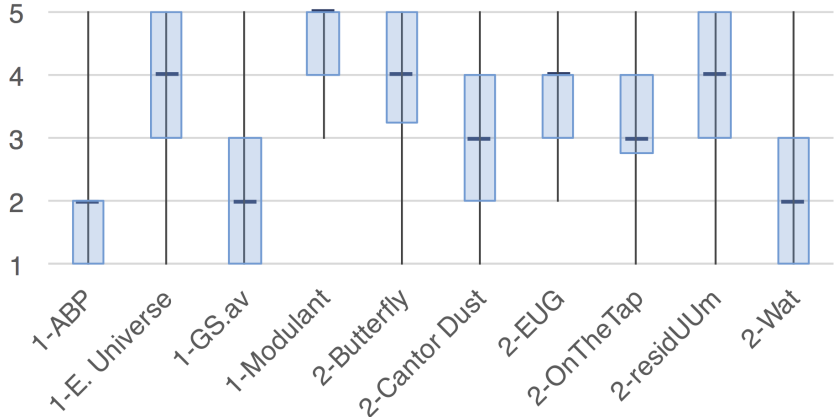

Figure 3: Boxplot with results from audience understanding of performers actions in Gen.AV 1 and 2 projects (5-point Likert scale in y-axis).

to understand how user input affects sound". A respondent found it clearer than the "conventional" live coding: "the next layer for live coders to add to their tool kit, such that the audience get more of an understanding of the process being instigated on stage, rather than seeing just code (only select audiences can read such code)".

The UI quadrants of Butterfly, with its XY parametric space and four "butterfly" icons representing the current state, seems to have been also been clear to the audience, as confirmed by the following observations: "largely comprehensible via point and click style GUI”; "moving 'bow-ties' [butterflies] to control the music"; "this was clear by seeing the cursor moving the individual butterflies"; "cursor movement in XY space with animated bars made for clean interaction"; and "really clear".

residUUm was praised for its stylized cursor: "a nice cursor, much better than other performances' quotidian cursor", pointing in the same direction of some of the expert observations regarding the stylistic integration of the GUI with the visuals. Despite the success of the cursor in residUUm in attracting attention and conveying interaction, not all aspects of mechanics behind the software were made clear, raising further questions: "The cursor was a focal point when moved the visuals changed. Maybe click and hold cursor makes it louder?". The issue of UI stylization (or lack of) is also implicit regarding OnTheTap: "Clear but basic in terms of its interaction. It would have been nice to see a more elegant solution rather than sliders".

Some contrasting comments highlighted more negative aspects regarding visible interaction. While some respondents enjoyed seeing the cursor and the controls, others find viewing a cursor on the screen unappealing: "not nice to see a mouse cursor in a live performance" (Esoterion Universe). Also, some respondents found one project (the highest scoring one in this regard, Modulant) too clear in its interaction: 
"Perhaps too much [understandable]. Not very fluid, but synchronized. Simple."; "didactic"; and "like a demo".

Not all understanding of the performance was conveyed by the visuals. When information was lacking on the screen, the audience appeared to want to read what the performer was doing from his/her body, as illustrated by the following statements: "It was not possible to see their actions. Maybe use some cameras next time" (AVP); "Not clear because I could not see the performer" (GS.avi); "hard to understand as I could not tell what was being done by the performer" (Wat). In some cases, the understanding only occurred during the post-performance explanation: "I didn't understand what was going on until I was told" (GS.avi); "when I heard the explanation about tap it was interesting but didn't see it in performance" (OnTheTap).

\section{DISCUSSION}

Visibility of interface and of the parameter space - the interval of values a parameter can have, and its current position on that interval - seem to have contributed to audience understanding. Four of the five projects that achieved the highest scores in the questionnaire (medians of 4 and 5) made visible both the interface and the parameter space. One of these five projects, residUUm, did not show a graphical interface, but highlighted the agency of the performer with a stylized cursor, and showed the parameter space. Cantor Dust and OnTheTap, both with a median of 3, implemented only one of these aspects (visibility of parameter space, in Cantor Dust) or only temporarily showed them (OnTheTap). The remaining projects, with a median of 2 , employed neither.

We will now identify design solutions which have led to better results with audience members. Our outcomes point to a higher audience understanding within the categories, or design patterns, of audiovisual entities and sounding figurations. We firstly analyze elements within each of the categories that offer potential for audience understanding.

Regarding audiovisual entities, four aspects have been explicitly mentioned by audience members: 1) the visibility of the interface per entity or module; 2) the stylization of the GUI; 3) the parameter space of that interface; 4) the legibility of performer's actions through the cursor. All four audiovisual entities projects followed these aspects (with the exception of residUUm, which did not implement aspect 1).

Concerning sounding figurations, the open-ended comments of audience members regarding Modulant mention important aspects to take into account for these types of projects. Although understanding in Modulant was very high, both as reflected in its score and in open-ended comments, not all respondents were pleased with the transparency and direct mapping between drawing and sound. This raises the issue if, after a certain threshold, a high understanding of the performance might be detrimental to the experience, making it appear less like an act of expression and more as a technical demonstration. As recommended by Levin when discussing painterly interfaces, it might be beneficial to "eschew mappings based on the arbitrary conventions of visual language, or the arbitrary affordances of computational technologies", and pursue more dynamic mappings, using gesture and correspondent animation properties such as velocity, orientation and curvature [24].

The analysis of the results allows us to propose best practices for the design of live visuals leading to better audience understanding in performances:

- Adopt a design pattern based on audiovisual entities or sounding figurations. Both patterns create a direct link between interaction and result. In the case of audiovisual entities, this connection is apparent by creating multiple 'objects' consisting of corresponding audio and visual elements, which can be controlled independently. In the case of sounding figurations, the connection comes from consistent mapping strategies between the act of drawing or the resulting figure, and a sonic result.

- For the audiovisual entities design pattern, ensure that: 1) each audiovisual module has a visible corresponding interface (and not an overall UI or control panel, as usually happens in AV software); 2) the graphic design of the interface matches the aesthetic of the visuals, to create a coherent whole; 3 ) the parameter space is visible for each module (minimum, maximum and current status of the parameters); 4) the agency of the performer is present on the screen, but in a stylized way to avoid a "demo effect" (for example, with a customized cursor or symbolic representation of multitouch). Recommendations 1-3, on the whole, match the concept of AVUI [11].

- Regarding a sounding figurations design pattern, do not employ a simplistic approach, which might appear over overly demonstrative. This can be accomplished by avoiding direct one-to-one mappings between points on the screen and audio properties, and introducing dynamic elements (speed, orientation etc) from the gesture generating the drawing.

We have analyzed the importance of visuals to communicate interaction information to the audience. But there are other factors in audiovisual performance, external to the visuals, that contribute to audience understanding. We identify three: 1) the body of the performer; 2) the eventual explanation by the performer; and 3) the characteristics of the setting and the audience itself. Even in laptop-based performances, the audience looks for visual cues from the body of the performer. We found that this was particularly the 
case when the visuals did not assist in communicating the performer's actions.

Another element that influences audience understanding is the artist explanation. In our events, we asked performers to explain their pieces to the audience, after their performance. Our results suggest that these explanations influence audience understanding as well. However, we believe that it did not overly influence the results for this study, as audience members distinguished between meaning acquired from explanation and from the performance itself.

One last external element is the setting for the performance, and the profile of the audience itself. These seem to us related, as from our experience, a certain setting tends to attract a determined profile, forming a loose community. For example, in our case the performances took place in Goldsmiths, University of London, a university well known for its art and musical studies. That would lead to a more knowledgeable audience regarding performative practices, electronic music and audiovisuals. Our experience also tells us that there is a specialized audience for laptop electronic music and audiovisual performance, particularly in larger urban environments. More research should be conducted on characterizing audiences for audiovisual performances.

\section{CONCLUSIONS}

We have addressed the issue of audience understanding in laptop-based music performances with live visuals. We analyzed this topic, from the perspective of audience members, in two events (10 different audiovisual projects presented in total). Our results confirmed the polysemic nature intrinsic to the interpretative process of cultural objects.

We have presented best practices in the design of software for audiovisual performance leading to audience understanding, regarding two identified successful design patterns audiovisual entity and sounding figurations - which relate to our concept of AVUI. We have also identified additional factors that influence audience understanding in laptop-based performance, and that deserve attention for future work: body of performer; performance explanation; and community (audience-setting).

Even though questionnaires are one of the most common methods used to understand audience response to an event [7], a more multi-layered approach would have allowed us to dig deeper in the process of audience understanding. In addition, gathering more information about the profile of the attendees would have helped in the interpretation of the data collected. For example, by exploring further their level of familiarity with the cultural object, their pre-formed taste, their prior judgment and, even, the expectation with which they arrive to the event. More data could be gathered in the future with a more diverse audience. Future research could aim at studying more examples of each project category, particularly within sounding figurations (only one example, Modulant, was included in this category). The projects presented are merely case-studies within each category, and their representativeness could be reinforced in the future with more examples.

We believe that more research needs to be carried out within the topic of live visuals and audience understanding, especially due to the identified limitations of laptop-based performance in terms of visual feedback, and the potential of live visuals to address that. Additional questions to be asked are: Does the live coding mode also satisfy audience communication? And: Does electronic music benefit from visuals, or are there other approaches conductive for audience understanding - such as augmenting 'traditional' instruments, or more emphasis on gestural control? Lastly: How does understanding relate to the overall audience enjoyment? Another aspect that deserves attention is how the reported experience of the audience might influence the work of the performers, or even, those members of the audience who are also practitioners. This idea not only aligns with the outcomes of the present paper, focused on "understanding", but also emphasizes the complexity of the concept of "experience". According to Reason [30], "experience" is not merely "what is going on in an audience's mind (and body) during a performance, but also is what they do with this experience after the event". This particular perspective on the audience has been mostly neglected, even though it is here "where there is rich potential for developing strong, creative and self-reflective methodological approaches" [30]. This provides with a path for future work - to adopt a broader perspective of audience experience, during and after the event.

There is a growing interest in audience participation in performances, and we maintain that understanding is a crucial condition for successful participation. Live visuals can be more than "blinking lights" [21] or an overpowering element [22] - they have the potential to successfully augment the electronic music performer, contributing to audience understanding.

\section{ACKNOWLEDGEMENTS}

We would like to thank all who collaborated in this research - hackathon participants, performers and audience members. This work was supported by the EU Marie Curie fellowship FP7 REA grant 627922 and also partly by FCT/MCTES LARSyS (UID/EEA/50009/2013 (2015-2017)) and MITI/Excell (M1420-01-0145-FEDER-000002-MITIExcell).

\section{REFERENCES}

[1] Saul Albert. 2015. Rhythmical coordination of performers and audience in partner dance. Delineating improvised and choreographed interaction. Etnografia e ricerca qualitativa 3/2015 (2015). https: //doi.org/10.3240/81723 
[2] Jerônimo Barbosa, Filipe Calegario, Veronica Teichrieb, Geber Ramalho, and Patrick McGlynn. 2012. Considering Audience's View Towards an Evaluation Methodology for Digital Musical Instruments. In Proc. NIME 2012. Ann Arbor. http://www.nime.org/proceedings/2012/nime2012_ 174.pdf

[3] Florent Berthaut, Mark T. Marshall, Sriram Subramanian, and Martin Hachet. 2013. Rouages: Revealing the Mechanisms of Digital Musical Instruments to the Audience. In Proc. NIME 2013. Daejeon, Seoul. http: //nime.org/proceedings/2013/nime2013_51.pdf

[4] S. Astrid Bin, Nick Bryan-Kinns, and Andrew P. Mcpherson. 2016 Skip the Pre-Concert Demo: How Technical Familiarity and Musical Style Affect Audience Response. In Proc. NIME 2016. 200-205. http: //www.nime.org/proceedings/2016/nime2016_paper0041.pdf

[5] Jay David Bolter and Richard Grusin. 2000. Remediation: Understanding New Media. The MIT Press, Massachusetts.

[6] Ana Carvalho and Cornelia Lund (Eds.). 2015. The Audiovisual Breakthrough. Fluctuating Images, Berlin. http://www.ephemeral-expanded. net/audiovisualbreakthrough/

[7] Pablo Cesar, Jack Jansen, Erik Geelhoed, Doug Williams, Ian Kegel, Marian F. Ursu, and Chen Wang. 2015. Distributed Theatre: Connecting (with) Remote Audiences. In Proceedings of the Workshop on Everyday Telepresence: Emerging Practices and Future Research Directions, in conjuncion with the ACM SIGCHI Conference on Human Factors in Computing Systems. Seoul.

[8] Nick Collins, Alex McLean, Julian Rohrhuber, and Adrian Ward. 2003. Live Coding in Laptop Performance. Org. Sound 8, 3 (Dec. 2003), 321-330. https://doi.org/10.1017/S135577180300030X

[9] Nuno N. Correia and Atau Tanaka. 2014. User-Centered Design of a Tool for Interactive Computer-Generated Audiovisuals. In Proc. 2nd ICLI. Lisbon. http://www.liveinterfaces.org/proceedings2014.html

[10] Nuno N. Correia and Atau Tanaka. 2015. Prototyping Audiovisual Performance Tools: A Hackathon Approach. In Proc. NIME 2015. Baton Rouge, Louisiana. http://www.nime.org/proceedings/2015/nime2015 230.pdf

[11] Nuno N. Correia and Atau Tanaka. 2017. AVUI: Designing a Toolkit for Audiovisual Interfaces. In Proceedings of the 2017 CHI Conference on Human Factors in Computing Systems (CHI '17). ACM, New York, NY, USA, 1093-1104. https://doi.org/10.1145/3025453.3026042

[12] Bram Crevits. 2006. The Roots of VJing. In V7: Audio-Visual Art and Vf Culture, Michael Faulkner (Ed.). Laurence King Publishing, London, 14-19.

[13] Lucy K. Dearn and Stephanie E. Pitts. 2017. (Un) popular music and young audiences: Exploring the classical chamber music concert from the perspective of young adult listeners. Fournal of Popular Music Education 1, 1 (2017), 43-62. https://doi.org/10.1386/jpme.1.1.43

[14] Umberto Eco. 1993. Lector in Fabula (2nd edition ed.). Fabbri, Milano.

[15] William A. Evans. 1990. The interpretative turn in media research: innovation, iteration, or illusion? Critical Studies in Mass Communication 7 (1990), 147-168.

[16] Sidney Fels, Ashley Gadd, and Axel Mulder. 2002. Mapping transparency through metaphor: towards more expressive musical instruments. Organised Sound 7, 02 (2002), 109-126. https://doi.org/10.1017/ S1355771802002042

[17] Wendy Griswold, Elizabeth Lenaghan, and Michelle Naffziger. 2011. Readers as Audiences. In The Handbook of $\mathrm{Me}$ dia Audiences, Virginia Nightingale (Ed.). Wiley-Blackwell, 1740. http://onlinelibrary.wiley.com/doi/10.1002/9781444340525.ch1/ summary DOI: 10.1002/9781444340525.ch1.

[18] Michael Gurevich and A. Cavan Fyans. 2011. Digital Musical Interactions: Performer-system relationships and their perception by spectators. Organised Sound 16, 2 (2011), 166-175. https://doi.org/10.1017/ S1355771811000112
[19] Stuart Hall. 1999. Encoding, Decoding. In The Cultural Studies Reader. 507-517.

[20] Javier Jaimovich, Miguel Ortiz, Niall Coghlan, and R Benjamin Knapp. 2012. The Emotion in Motion Experiment: Using an Interactive Installation as a Means for Understanding Emotional Response to Music. In Proc. NIME 2012. 457-458. http://www.nime.org/proceedings/2012/ nime2012_254.pdf

[21] Vitor Joaquim and Álvaro Barbosa. 2013. Are Luminous Devices Helping Musicians to Produce Better Aural Results, or Just Helping Audiences Not To Get Bored?. In $x \operatorname{CoAx} 2013$ : Proceedings of the first conference on Computation, Communication, Aesthetics and X. http: //2013.xcoax.org/\#p36

[22] Sergi Jordà. 2005. Digital Lutherie - Crafting Musical Computers for New Musics' Performance and Improvisation. PhD thesis. UPF, Barcelona. http://mtg.upf.edu/node/449

[23] Chi-Hsia Lai and Till Bovermann. 2013. Audience Experience in Sound Performance. In Proc. NIME 2013. 170-173. http://nime.org/ proceedings/2013/nime2013_197.pdf

[24] Golan Levin. 2000. Painterly Interfaces for Audiovisual Performance. Ph.D. Dissertation. M.Sc. Dissertation. Massachusetts Institute of Technology, Cambridge, MA. http://acg.media.mit.edu/people/golan/thesis/ thesis300.pdf

[25] William Moritz. 2004. Optical Poetry: The Life and Work of Oskar Fischinger. John Libbey Publishing, Eastleigh.

[26] Glenn O’Brien. 2005. Tune In, Turn On, Light Up... Tate Etc. 4 (2005). http://www.tate.org.uk/tateetc/issue4/summeroflove.htm

[27] Ireti Olowe, Giulio Moro, and Mathieu Barthet. 2016. residUUm: user mapping and performance strategies for multilayered live audiovisual generation. In Proc. NIME 2016. Brisbane. http://www.nime.org/ proceedings/2016/nime2016_paper0053.pdf

[28] Friedrich Platz and Reinhard Kopiez. 2012. When the eye listens: A meta-analysis of how audio-visual presentation enhances the appreciation of music performance. Music Perception 30, 1 (2012), 71-83. https://doi.org/10.1525/mp.2012.30.1.71

[29] Jennifer Radbourne, Katya Johanson, Hilary Glow, and Tabitha White. 2009. The Audience Experience: Measuring Quality in the Performing Arts. International Journal of Arts Management 11, 3 (2009), 16-29. http://www.jstor.org/stable/41064995http://about.jstor.org/terms

[30] Matthew Reason. 2010. Asking the audience: audience research and the experience of theatre. About performance 10 (2010), 15-34. https: //ray.yorksj.ac.uk/id/eprint/381/

[31] Dee Reynolds. 2011. Watching Dance: Kinesthetic Empathy. (2011). http://www.watchingdance.org/

[32] Luísa Ribas. 2011. The Nature of Sound-Image Relations in Digital Interactive Systems. PhD thesis. Universidade do Porto Faculdade de Belas Artes, Porto.

[33] Chris Salter. 2010. Entangled: Technology and the Transformation of Performance. MIT Press, Massachusetts.

[34] Jonna K. Vuoskoski, Marc R. Thompson, Charles Spence, and Eric F. Clarke. 2016. Interaction of Sight and Sound in the Perception and Experience of Musical Performance. Music Perception: An Interdisciplinary Journal 33, 4 (April 2016), 457-471. https://doi.org/10.1525/ mp.2016.33.4.457

[35] Richard Wagner. 2001. Outlines of the Artwork of the Future. In Multimedia: From Wagner to Virtual Reality, Randall Packer and Ken Jordan (Eds.). W. W. Norton, New York, 3-9.

[36] Brita B. Wheeler. 2004. The social construction of an art field: how audience informed the institutionalization of performance art. The fournal of Arts Management, Law, and Society 33, 4 (2004), 336-350. https://doi.org/10.3200/JAML.33.4.336-350 